\title{
Comparative analysis of human mesenchymal stem cells from bone marrow and adipose tissue under xeno-free conditions for cell therapy
}

Chun-yu Li ${ }^{1,2}$, Xiao-yun Wu ${ }^{3}$, Jia-bei Tong ${ }^{4}$, Xin-xin Yang ${ }^{5}$, Jing-li Zhao ${ }^{6}$, Quan-fu Zheng ${ }^{1,2}$, Guo-bin Zhao ${ }^{7}$ and Zhi-jie $\mathrm{Ma}^{8^{*}}$

\begin{abstract}
Introduction: Mesenchymal stem cells (MSCs) are promising candidates for cell-based therapies. Human platelet lysate represents an efficient alternative to fetal bovine serum for clinical-scale expansion of MSCs. Different media used in culture processes should maintain the biological characteristics of MSCs during multiple passages. However, bone marrow-derived MSCs and adipose tissue-derived MSCs have not yet been directly compared with each other under human platelet lysate conditions. This study aims to conduct a direct head-to-head comparison of the biological characteristics of the two types of MSCs under human platelet lysate-supplemented culture conditions for their ability to be used in regenerative medicine applications.
\end{abstract}

Methods: The bone marrow- and adipose tissue-derived MSCs were cultured under human platelet lysate conditions and their biological characteristics evaluated for cell therapy (morphology, immunophenotype, colony-forming unit-fibroblast efficiency, proliferation capacity, potential for mesodermal differentiation, secreted proteins, and immunomodulatory effects).

Results: Under human platelet lysate-supplemented culture conditions, bone marrow- and adipose tissue-derived MSCs exhibited similar fibroblast-like morphology and expression patterns of surface markers. Adipose tissue-derived MSCs had greater proliferative potential than bone marrow-derived MSCs, while no significantly difference in colony efficiency were observed between the two types of cells. However, bone marrow-derived MSCs possessed higher capacity toward osteogenic and chondrogenic differentiation compared with adipose tissue-derived MSCs, while similar adipogenic differentiation potential wase observed between the two types of cells. There were some differences between bone marrow- and adipose tissue-derived MSCs for several secreted proteins, such as cytokine (interferon- $\gamma$ ), growth factors (basic fibroblast growth factor, hepatocyte growth factor, and insulin-like growth factor-1), and chemokine (stem cell-derived factor-1). Adipose tissue-derived MSCs had more potent immunomodulatory effects than bone marrow-derived MSCs.

Conclusions: Adipose tissue-derived MSCs have biological advantages in the proliferative capacity, secreted proteins (basic fibroblast growth factor, interferon- $\gamma$, and insulin-like growth factor- 1 ), and immunomodulatory effects, but bone marrow-derived MSCs have advantages in osteogenic and chondrogenic differentiation potential and secreted proteins (stem cell-derived factor-1 and hepatocyte growth factor); these biological advantages should be considered systematically when choosing the MSC source for specific clinical application.

\footnotetext{
* Correspondence: 13811647091@163.com

${ }^{8}$ Department of Pharmacy, Beijing Friendship Hospital, Capital Medical University, Beijing 100050, China

Full list of author information is available at the end of the article
} 


\section{Introduction}

Mesenchymal stem cells (MSCs) hold great promise in the field of regenerative medicine based on their abilities of self-renewal and multilineage differentiation [1]. Over the past decade, MSCs which are isolated from the umbilical cord, umbilical cord blood, bone marrow (BM), adipose tissue (AT) and many other adult tissues have been explored as potential therapeutic strategies for a number of diseases [2], but AT and BM are the most widely used sources of MSC, especially in autologous cell-based therapies due to ease of harvest and potential autologous application [3]. Moreover, there are a relative abundance of progenitors and a lack of ethical concerns. However, one important question that remains to be answered is which cell is more effective and suitable for cell therapy. Many studies have shown that BMMSCs and ATMSCs share similar features, including the morphologic features and the expression of cell surface antigens, but significant biologic differences have been observed concerning their proliferation rates and differentiation capacities [4-9]. Conflicting results have been reported, with some indicating that the clinical application potential of ATMSCs is more effective or as effective as that of BMMSCs, while others conclude that BMMSCs are superior to ATMSCs [7,10-13]. Moreover, there are significant differences between ATMSCs and BMMSCs in the cytokine secretome and chemokine receptor expression $[10,14,15]$, which may provide clues to alternative cell sources. One study has demonstrated that ATMSCs are more resistant to in vitro apoptosis than BMMSCs [11].

In these studies, comparative analysis of BMMSCs and ATMSCs is performed in medium supplemented with fetal bovine serum (FBS). FBS is an animal source product, and its use is undesirable due to potential transmission of animal pathogens and the risk that antibodies against FBS are developed, leading to rejection of the transfused cells [16]. In fact, as much as 20 to $50 \%$ of commercial FBS is virus-positive [17]. It has been shown that a single preparation of $10^{8}$ MSCs grown in FBS can carry approximately 7 to $30 \mathrm{mg}$ FBS proteins [18]. At present, the main alternative to FBS-supplemented medium is the use of human reagents enriched with growth factors, namely human platelet lysate (hPL), which increases safety by excluding xenogeneic proteins.

The usage of hPL in MSC culture provides the following advantages: 1) hPL as a human reagent lacks any risk of secondary effects which may be caused by FBS constituents in culture [19]; and 2) platelet rich plasma (PRP) as a source of hPL can be directly implemented for clinical applications since it is Good Manufacturing Practice-approved without extensive testing $[20,21]$.

Several previous studies have been conducted to compare the biological characteristics of BMMSCs and
ATMSCs between two different supplemented culture conditions (FBS versus hPL) [20,22-26]. Based on efficiency and safety, hPL can replace FBS for clinical-scale expansion of functional BMMSCs and ATMSCs for therapeutic applications. Most of the studies report that the growth factor-enriched hPL has considerable growth-promoting properties for MSCs while maintaining their immunophenotype, differentiation potential and immunomodulatory properties $[20,23,26]$. However, one study reports that MSCs show an increase in osteogenic differentiation and a decrease in adipogenic differentiation when cultured in hPL-supplemented medium [26]. Moreover, a report illustrates that hPL alters the expression of some relevant MSC surface molecules and leads to a decreased inhibitory capacity on $\mathrm{T}$ cell and natural killer cell proliferation and function compared to FBS [27].

Therefore, the medium used is crucial for the safety and efficacy of MSC culture, and different media used in the culture processes should maintain the different phenotype, differentiation potential, and functions of MSCs during multiple passages [28]. However, BMMSCs and ATMSCs have not yet been directly compared with each other under hPL conditions for their ability to be used in regenerative medicine applications.

Increasing evidence supports the generalization that stem cell therapy produces generally positive effects largely via secretion of various cytokines, such as growth factors, cytokines and chemokines, involving anti-scarring, antiapoptotic, angiogenesis, immunomodulatory and chemoattractant functions [29-31].

The aim of this study is to conduct a direct head-tohead comparison of the following biological characteristics of the two types of MSC: morphology, immunophenotype, colony-forming unit-fibroblast (CFU-F) efficiency, proliferation capacity, potential for mesodermal differentiation, and expression of several well-characterized growth factors, cytokines and chemokines in vitro. To the best of our knowledge, this is the first study that directly compares human BMMSCs and ATMSCs under hPL conditions. Such information may be crucial for identifying a more suitable cell source for a given clinical application.

\section{Materials and methods}

\section{Medium preparations}

hPL was prepared as previously described [32]. Briefly, PRP, obtained from one healthy volunteer at the Hospital Transfusion center, was standardized to a concentration of approximately $1 \times 10^{9}$ platelets $/ \mathrm{mL}$, and then PRP was frozen down to $-80^{\circ} \mathrm{C}$ and subsequently thawed at $37^{\circ} \mathrm{C}$ to obtain platelet-released growth factors. Lysed PRP (20 units) was pooled to avoid individual donor variations. hPL was centrifuged at 4,000 g for 15 minutes at $4^{\circ} \mathrm{C}$ to remove the platelet fragments. The supernatant 
plasma was filtered further using a $0.22-\mu \mathrm{m}$ filter (BD Biosciences, San Jose, CA, USA) and added to heparinized Iscove's modified Dulbecco's medium (IMDM; $2 \mathrm{U} / \mathrm{mL}$ ).

\section{Human bone marrow- and adipose tissue-derived mesenchymal stem cell cultures}

All samples were obtained from healthy donors with informed consent, and the study was approved by the Ethics Committee of Military 302 Hospital of China.

BMMSC cultures were established as previously described [8]. Briefly, BM aspirates $(25 \mathrm{~mL})$ were collected from five volunteers aged 18 to 30 years. BM was layered over a lymphoprep gradient and centrifuged at 2,000 rpm for 30 minutes. Mononuclear cells were washed twice with phosphate-buffered saline (PBS) and plated at a concentration of $2 \times 10^{5} / \mathrm{cm}^{2}$ in $75 \mathrm{~cm}^{2}$ flasks for 2 days in $5 \%$ hPL-supplemented medium. After removing nonadherent cells, the adherent cells were maintained at $37^{\circ} \mathrm{C}, 5 \% \mathrm{CO}_{2}$. The medium was subsequently changed twice a week.

ATMSCs were isolated by enzymatic digestion as previously described [33]. Briefly, lipoaspirate tissues $(25 \mathrm{~mL})$ were harvested from five volunteers and washed with PBS in a 50-mL Falcon tube. The tissues were then digested with an equal volume of $0.2 \%$ collagenase type IV at $37^{\circ} \mathrm{C}$ for 30 minutes, and the stromal vascular fraction cells isolated by centrifugation at $300 \times \mathrm{g}$ at room temperature. Viable cells $\left(1 \times 10^{6}\right)$ were cultured in $75 \mathrm{~cm}^{2}$ flasks in $5 \%$ hPL-supplemented medium. After 2 days, the unattached cells were depleted by replacing the medium with fresh medium. The medium was subsequently changed twice a week.

At 80 to $90 \%$ confluence, both types of cells were harvested with trypsin-ethylenediaminetetraacetic acid and subsequently replated at 2,000 cells $/ \mathrm{cm}^{2}$.

\section{Proliferation studies}

To compare the proliferative potential of BMMSCs and ATMSCs, both types of cells were serially passaged and counted when a subconfluence of 80 to $90 \%$ was reached. The mean population doubling $(\mathrm{PD})$ was determined for each passage using the following formula:

$$
P D=\frac{[\log 10(N h)-\log 10(N p)]}{\log 10(2)}
$$

where $N_{h}$ is the collected cell number and $N_{p}$ is the plated cell number. The PD for each passage was added to the PD of the previous passages to give cumulative population doubling (CPD).

\section{Colony-forming unit-fibroblast assays}

To assess the capacity for self-renewal of BMMSCs and ATMSCs, the CFU-F assay was performed as previously described [34]. Briefly, single-cell suspensions at passage
1 were plated in six-well culture plates in IMDM (5\% hPL) at densities of $1 \times 10^{3}$ per well. On day 14, the cell layer was fixed with methanol and stained with crystal violet. Individual colonies composed of at least 50 cells were counted.

\section{Flow cytometry analysis}

For the analysis of surface marker expression of BMMSCs and ATMSCs, both types of cells at passage 5 were washed three times with PBS, and then incubated with a blocking solution of $3 \%$ serum in PBS for $30 \mathrm{mi}-$ nutes. After centrifugation, $5 \times 10^{5}$ cells were suspended in blocking solution, then stained with antibodies against human CD14, CD19, CD90, CD105, HLA-DR, CD29, CD13, CD34, CD45 and HLA-ABC (BD Biosciences). After incubation for 30 minutes, the cells were washed with $\mathrm{PBS}$, and then analyzed by flow cytometry on a FACSCalibur (Becton Dickinson, San Jose, CA, USA) following standard procedures.

\section{Multilineage differentiation and staining assay}

To assess the differentiation potential of BMMSCs and ATMSCs, both types of cells at passage 5 were differentiated into adipocyte, osteoblast, and chondrocyte phenotypes.

For osteogenic differentiation, BMMSCs and ATMSCs were seeded at $5 \times 10^{3}$ cells $/ \mathrm{cm}^{2}$ for 24 hours, and then cultured in the osteogenic differentiation medium containing 5\% hPL, $100 \mathrm{nM}$ dexamethasone, $50 \mu \mathrm{M}$ ascorbate-2-phosphate, and $10 \mathrm{mM} \beta$-glycerophosphate in Dulbecco's modified Eagle's medium (DMEM). The differentiation medium was subsequently changed twice a week. After 21 days, osteogenic differentiation was assessed by Alizarin Red staining of calcium phosphate deposits.

For adipogenic differentiation, BMMSCs and ATMSCs were seeded at $2 \times 10^{4}$ cells $/ \mathrm{cm}^{2}$ for 24 hours, and then cultured in the adipogenic differentiation medium containing 5\% hPL, $1 \mu \mathrm{M}$ dexamethasone, $0.2 \mathrm{mM}$ indomethacin, $0.5 \mathrm{mM}$ isobutyl-1-methylxanthine, and $10 \mathrm{mg} / \mathrm{L}$ insulin in DMEM. The differentiation medium was subsequently changed twice a week. After 21 days, adipogenic differentiation was assessed by Oil Red O staining of the fatty vacuoles.

For chondrogenic differentiation, 5- $\mu$ l droplets of cell solution of $2 \times 10^{7}$ cells $/ \mathrm{mL}$ were seeded in the center of a multi-well plate to form a micromass cultures for 2 hours, and then cultured in the chondrogenic differentiation medium containing $10 \mathrm{mg} / \mathrm{L}$ insulin, $10 \mathrm{mg} / \mathrm{L}$ transferrin, $5 \mu \mathrm{g} / \mathrm{L}$ sodium selenite, $100 \mathrm{nM}$ dexamethasone, $50 \mathrm{mg} / \mathrm{L}$ ascorbate-2-phosphate, $20 \mathrm{ng} / \mathrm{mL}$ transforming growth factor (TGF)- $\beta 3,40 \mathrm{mg} / \mathrm{L}$ L-proline, $3 \mathrm{mM}$ linoleic acid, $3 \mathrm{mM}$ oleic acid, and $4 \mathrm{~g} / \mathrm{L}$ human serum albumin in DMEM. The differentiation medium 
was subsequently changed twice a week. After 21 days, chondrogenic differentiation was assessed by Alcian Blue staining of sulfated proteoglycans.

\section{Real-time polymerase chain reaction analysis}

Real-time PCR was performed to detect the gene expression indicative of cell differentiation. Table 1 lists the primers that were used. Power SYBR Green PCR Master mix (Applied Biosystems, Fostrt City, CA, USA) was used under the following conditions: $50^{\circ} \mathrm{C}$ for 2 minutes, $95^{\circ} \mathrm{C}$ for 2 minutes, and then $95^{\circ} \mathrm{C}$ for 3 seconds and $60^{\circ} \mathrm{C}$ for 30 seconds for a total of 40 cycles. Results were analyzed using the $2^{-\Delta C t}$ method relating gene expression to $\beta$-actin.

\section{Enzyme-linked immunosorbent assay}

To compare protein secretion between BMMSCs and ATMSCs, the production of inflammatory cytokines (such as tumor necrosis factor (TNF)- $\alpha$, interferon (IFN)- $\gamma$, and interleukin (IL)-6), chemokines (such as stem cell-derived factor-1 (SDF-1) and IL-8), and growth factors (such as basic fibroblast growth factor (bFGF), hepatocyte growth factor (HGF), insulin-like growth factor (IGF)-1, and vascular endothelial growth factor (VEGF)) were measured. Both types of cells $\left(1 \times 10^{5}\right.$ cells/well $)$ at passage 5 were seeded on 24-well culture plates in hPL-free IMDM medium for 48 hours. The supernatants were collected, and the concentrations were measured with human enzyme-linked immunosorbent assay (ELISA) kits (R\&D, Minneapolis, MN, USA), according to the manufacturer's instructions.

\section{Mixed lymphocyte culture assays}

To quantify and compare the immunomodulatory effects of BMMSCs and ATMSCs, both types of cells were first

Table 1 Primer sequences for real-time PCR analysis and their respective product sizes

\begin{tabular}{|c|c|c|}
\hline Gene & Primer sequence $\left(5^{\prime}\right.$ to $\left.3^{\prime}\right)$ & $\begin{array}{l}\text { Product size } \\
\text { (bp) }\end{array}$ \\
\hline \multirow[t]{2}{*}{ RUNX-2 } & GGAGTGGACGAGGCAAGAGTIT & \multirow[t]{2}{*}{133} \\
\hline & AGCTTCTGTCTGTGCCTTCTGG & \\
\hline \multirow{2}{*}{$\begin{array}{l}\text { Alkaline } \\
\text { phosphatase }\end{array}$} & GGGAACGAGGTCACCTCCAT & \multirow[t]{2}{*}{67} \\
\hline & TGGTCACAATGCCCACAGAT & \\
\hline \multirow[t]{2}{*}{ SOX-9 } & GTACCCGCACTTGCACAAC & \multirow[t]{2}{*}{139} \\
\hline & GTAATCCGGGTGGTCCTTCT & \\
\hline \multirow[t]{2}{*}{ Collagen II } & GGCAATAGCAGGTTCACGTACA & \multirow[t]{2}{*}{79} \\
\hline & CGATAACAGTCTTGCCCCACTT & \\
\hline \multirow[t]{2}{*}{ PPARY } & GGCTTCATGACAAGGGAGTTC & \multirow[t]{2}{*}{74} \\
\hline & AACTCAAACTTGGGCTCCATAAAG & \\
\hline \multirow[t]{2}{*}{ LPL } & GAGGTACTITTCAGCCAGGATGTAAC & \multirow[t]{2}{*}{82} \\
\hline & AGCTGGTCCACATCTCCAAGTC & \\
\hline \multirow[t]{2}{*}{$\beta$-actin } & TGACGTGGACATCCGCAAAG & \multirow[t]{2}{*}{205} \\
\hline & CTGGAAGGTGGACAGCGAGG & \\
\hline
\end{tabular}

treated with mitomycin $\mathrm{C}(50 \mu \mathrm{g} / \mathrm{ml}$ for 50 minutes) to inactivate the proliferation. Next, human peripheral blood mononuclear cells were prepared by centrifugation on a Ficoll-Hypaque density gradient, and $2 \times 10^{5}$ cells of mononuclear cells were co-cultured with $2 \times 10^{3}$, $5 \times 10^{3}$, and $1 \times 10^{4}$ BMMSCs and ATMSCs per well in 96-well culture plate with $1 \mu \mathrm{g} / \mathrm{ml}$ anti-CD3 and antiCD28 T-cell activating mAbs (Life Technologies, Carlsbad, CA, USA) for 72 hours at $37^{\circ} \mathrm{C}$ and $5 \% \mathrm{CO}_{2}$. Conditioned medium was collected for the evaluation of indoleamine 2,3-dioxygenase (IDO) activity and prostaglandin $\mathrm{E}_{2}\left(\mathrm{PGE}_{2}\right)$ and TGF- $\beta$ quantification. $\mathrm{PGE}_{2}$ and TGF- $\beta$ concentrations were quantified using ELISA $(R \& D)$, according to the manufacturer's instructions. IDO activity was evaluated by Kynurenine levels as previously described [35]. Kynurenine levels are directly proportional to IDO activity.

\section{Statistical analysis}

The data are presented as the means \pm standard deviations of at least three experiments. Statistical analyses between groups were carried out using a Student's $t$-test. $P<0.05$ was considered to indicate a statistically significant difference.

\section{Results}

Morphology of bone marrow- and adipose tissue-derived mesenchymal stem cells

The adherent cells from BM and AT formed several colonies and exhibited a heterogeneous morphology with various shapes, including discoidal flat, triangular, and elongated. After passage 3, both types of cells became relatively homogeneous and showed a similar fibroblastlike (elongated spindle) morphology with abundant cytoplasm and large nuclei. BMMSCs and ATMSCs grew in parallel or vortex-like patterns, and no morphologic differences were observed in the final cell morphology (Figure 1).

\section{Proliferation capacity of bone marrow- and adipose tissue-derived mesenchymal stem cells}

CPD analysis showed that ATMSCs possessed higher CPD numbers for each passage, compared with BMMSCs (all $P<0.05$ ), indicating that ATMSCs had greater proliferative potential than BMMSCs (Figure 2A). At passage 5, CPD of ATMSCs and BMMSCs reached $13.7 \pm 0.5$ and $17.2 \pm 0.3$, respectively $(P<0.01)$.

CFU-F analyses showed no significant difference in colony counts between BMMSCs and ATMSCs $(P>0.05$; Figure $2 \mathrm{~B}$ ), although ATMSCs proliferated more rapidly than BMMSCs. Moreover, there were no significant differences in the cell number of each colony between BMMSCs and ATMSCs (data not shown). 


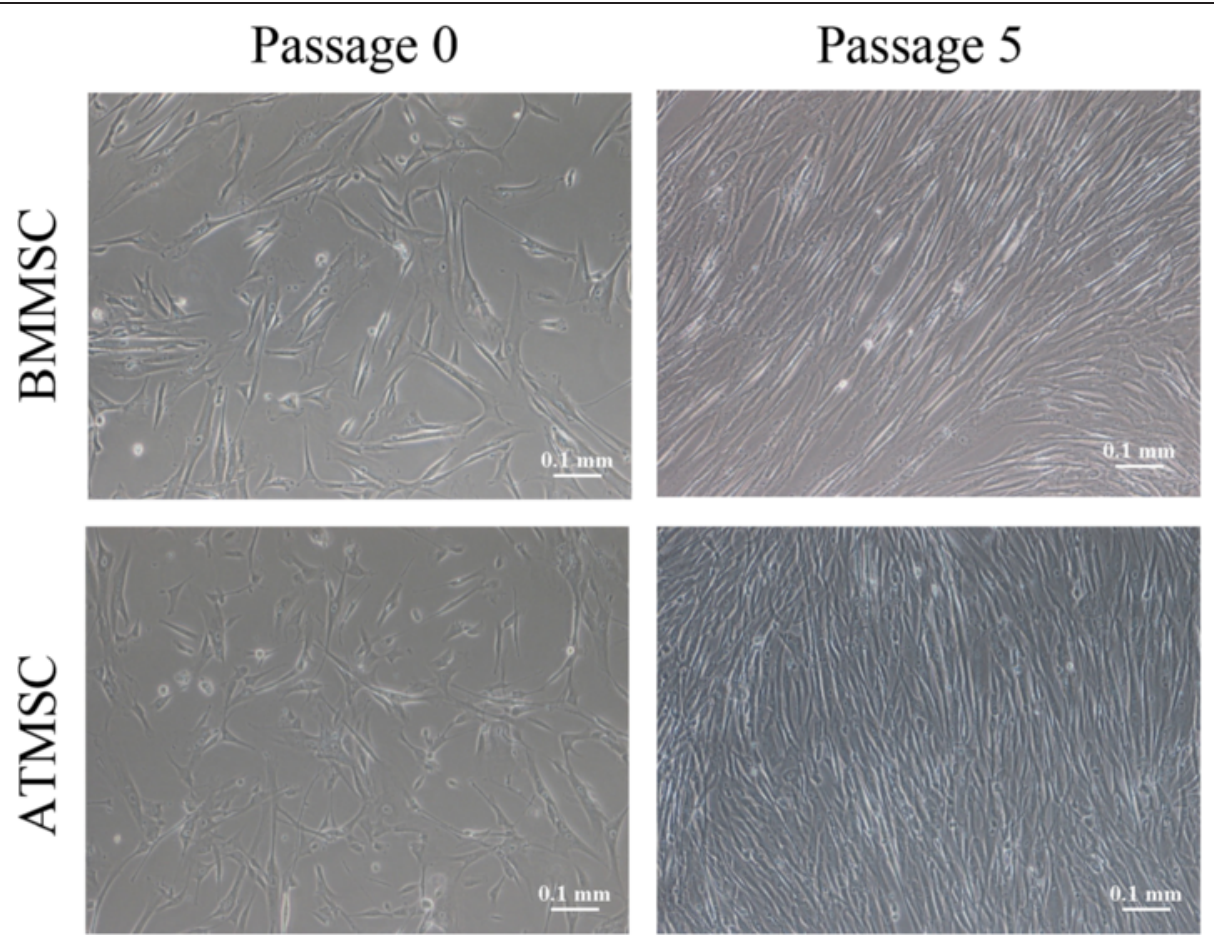

Figure 1 Morphology of bone marrow- (BMMSCS) and adipose tissue (ATMSCs)-derived mesenchymal stem cells cultivated in human platelet lysate-supplemented medium. BMMSCs and ATMSCs were tiny, slender, and bright. Scale bar $=100 \mu \mathrm{m}$.

Immunophenotypic analysis of bone marrow- and adipose tissue-derived mesenchymal stem cells

Flow cytometry analysis showed that BMMSCs and ATMSCs expanded in hPL-supplemented medium exhibited specific MSC markers (CD13, CD105) and cell adhesion molecules (CD29, CD90) at high levels (>85\%), and hematopoietic cell markers (CD14, CD19, CD34, CD45) molecules at very low levels $(<0.5 \%)$. Moreover, both types of cells expressed HLA-ABC (>85\%) but not HLA-DR $(<0.5 \%)$ (Table 2$)$. A representative phenotypic analysis of BMMSCs and ATMSCs is shown in Figure 3, demonstrating the homogeneity of the phenotype. In summary, BMMSCs and ATMSCs in hPL-supplemented medium reveal very similar expression patterns of surface markers.

Differentiation of bone marrow- and adipose tissue-derived mesenchymal stem cells into osteocytes, chondrocytes and adipocytes

To explore the differentiation potential towards osteoblasts, adipocytes, and chondrocytes of BMMSCs and ATMSCs expanded in hPL-supplemented medium, cytochemical staining and real-time PCR were performed to detect the cell differentiation capacity.

Calcium deposits of BMMSCs and ATMSCs after 21 days of differentiation were visualized by Alizarin Red staining, but the amount of staining was higher in BMMSCs than that in ATMSCs (Figure 4A). Furthermore, BMMSCs differentiated toward osteoblasts showed a statistically significant higher expression of RUNX-2 and alkaline phosphatase than ATMSCs (both $P<0.05$; Figure 4B). This indicates that BMMSCs have a higher osteogenic capability compared with ATMSCs.

Sulfated proteoglycans of BMMSCs and ATMSCs after 21 days of differentiation were visualized by Alcian Blue staining, but the amount of staining was higher in BMMSCs than that in ATMSCs (Figure 5A). Furthermore, BMMSCs differentiated toward chondrocytes showed a statistically significant higher expression of SOX-9 and collagen II than ATMSCs (both $P<0.01$; Figure 5B). This indicates that BMMSCs have a higher chondrogenic capability compared with ATMSCs.

Fatty vacuole deposits of BMMSCs and ATMSCs after 21 days of differentiation were visualized by Oil Red O staining; no significant differences in the amount of staining were observed between two types of cells (Figure 6A). Furthermore, the BMMSCs differentiated toward adipocytes showed statistically similar mRNA expression of PPAR $y$ and LPL as ATMSCs (both $P>0.05$; Figure 6B). This indicates that BMMSCs and ATMSCs have similar adipogenic capability.

\section{Expression analysis of cytokines, growth factors, and} chemokines of bone marrow- and adipose tissue-derived mesenchymal stem cells

To compare the protein secretion between BMMSCs and ATMSCs, ELISA was used to investigate the 


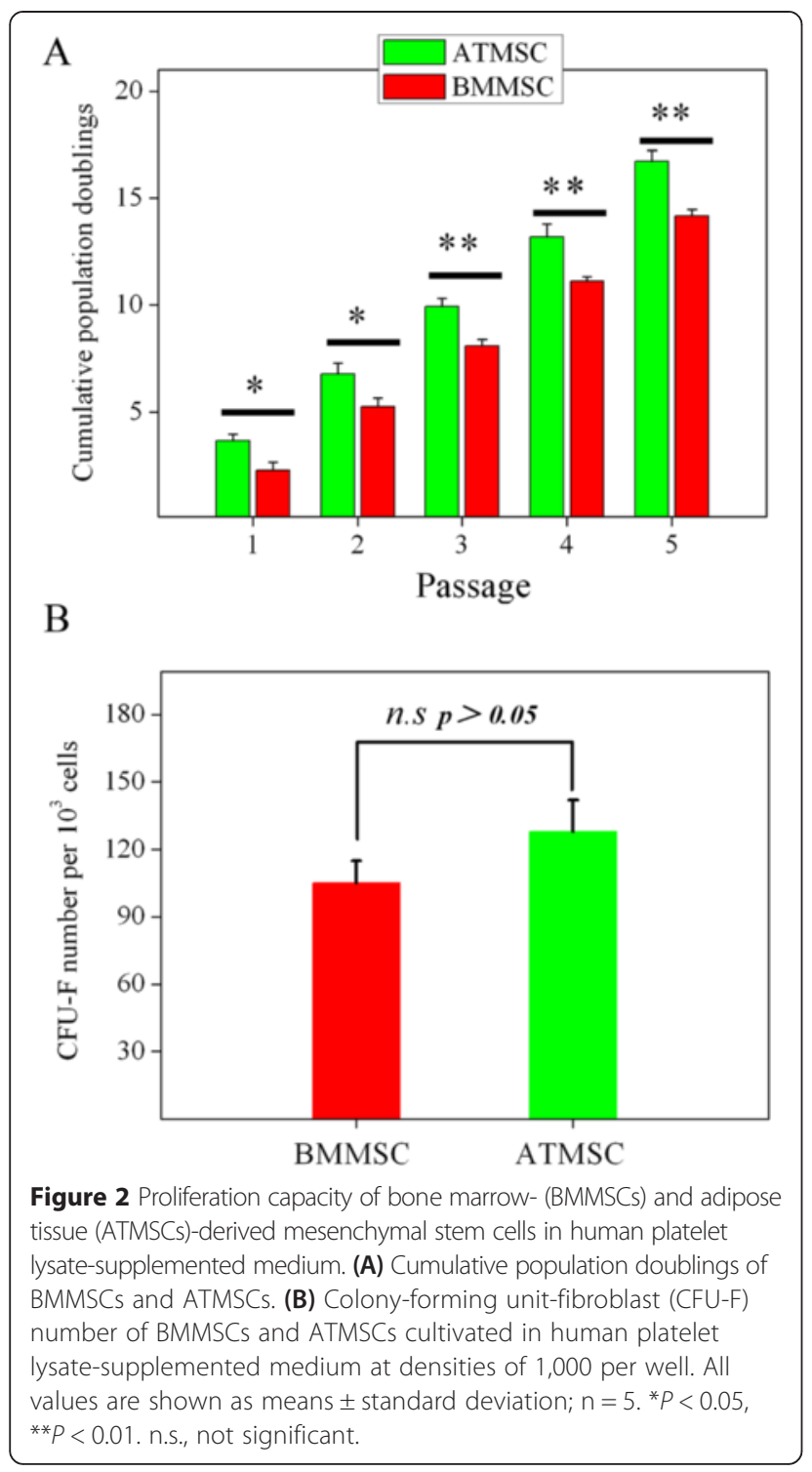

secretion of several cytokines, growth factors, and chemokines from ATMSC and BMMSC cultures. Compared with BMMSCs, ATMSCs secreted significantly greater amounts of IGF-1 $(P<0.01)$, bFGF $(P<0.05)$, and IFN- $\gamma$ $(P<0.05)$. On the other hand, BMMSCs secreted significantly greater amounts of SDF-1 $(P<0.01)$ and HGF $(P<0.01)$. However, there were no significant differences between ATMSCs and BMMSCs for several secreted factors, including inflammatory cytokines such as IL-6 and TNF- $\alpha$ [31], chemokines such as IL-8 [36], and growth and angiogenic factors such as VEGF [37] $(P>0.05$; Figure 7$)$.

\section{Immunomodulatory factor expression of bone marrow-} and adipose tissue-derived mesenchymal stem cells When cultured in three different MSC numbers, ATMSCs in hPL medium exhibited greater IDO activity
Table 2 Comparison of the expression of surface markers of bone marrow- (BMMSCs) and adipose tissue (ATMSCs)derived mesenchymal stem cells as analyzed by flow cytometry

\begin{tabular}{lll}
\hline Surface markers & \multicolumn{2}{l}{ Expression (\%) } \\
\cline { 2 - 3 } & BMMSCs $(\mathbf{n}=\mathbf{5})$ & ATMSCs $(\mathbf{n}=\mathbf{5})$ \\
\hline CD13 & $99.78 \pm 0.61$ & $99.17 \pm 0.57$ \\
CD29 & $98.36 \pm 0.50$ & $98.28 \pm 1.04$ \\
CD90 & $99.48 \pm 0.43$ & $99.03 \pm 0.47$ \\
CD105 & $87.38 \pm 0.62$ & $90.31 \pm 0.82$ \\
HLA-ABC & $94.34 \pm 1.51$ & $95.94 \pm 3.51$ \\
CD14 & $0.23 \pm 0.17$ & $0.18 \pm 0.20$ \\
CD19 & $0.16 \pm 0.08$ & $0.10 \pm 0.48$ \\
CD34 & $0.07 \pm 0.02$ & $0.05 \pm 0.04$ \\
CD45 & $0.08 \pm 0.03$ & $0.20 \pm 0.15$ \\
HLA-DR & $0.15 \pm 0.11$ & $0.26 \pm 0.17$ \\
\hline
\end{tabular}

(all $P<0.01$ ) compared with BMMSCs. However, no significantly difference in TGF- $\beta$ (all $P>0.05$ ) and PGE $_{2}$ (all $P>0.05$ ) secretion was observed between the two types of cell (Figure 8).

\section{Discussion}

Our findings demonstrate a number of findings. (1) BMMSCs and ATMSCs expanded in hPL-supplemented medium exhibit a homogeneous population with similar fibroblast-like (elongated spindle) morphology. (2) ATMSCs expanded in hPL-supplemented medium have greater proliferative potential than BMMSCs, while there are no significant differences in colony efficiency between the two types of cells. (3) BMMSCs and ATMSCs in hPL-supplemented medium reveal very similar expression patterns of surface markers. (4) BMMSCs expanded in hPL-supplemented medium possess higher capacity toward osteogenic and chondrogenic differentiation compared with ATMSCs, while they both have similar adipogenic differentiation potential. (5) There are some differences between BMMSCs and ATMSCs for several secreted proteins, such as cytokines, growth factors, and chemokines. (6) ATMSCs have more potent immunomodulatory effects than BMMSCs.

The plastic adherence capacity, surface marker expression, and multilineage differentiation potential towards osteoblasts, adipocytes, and chondrocytes have been proposed as minimal criteria to characterize human MSCs by the International Society for Cellular Therapy [38]. In the present study, we use hPL for production of MSCs and analyze all these parameters, and the results favor the "true MSC nature" of BMMSCs and ATMSCs. Moreover, the two types of cells exhibit homogeneous cell populations with a similar morphology and the expression of surface markers. Many investigators have demonstrated that MSCs isolated by adherence and 


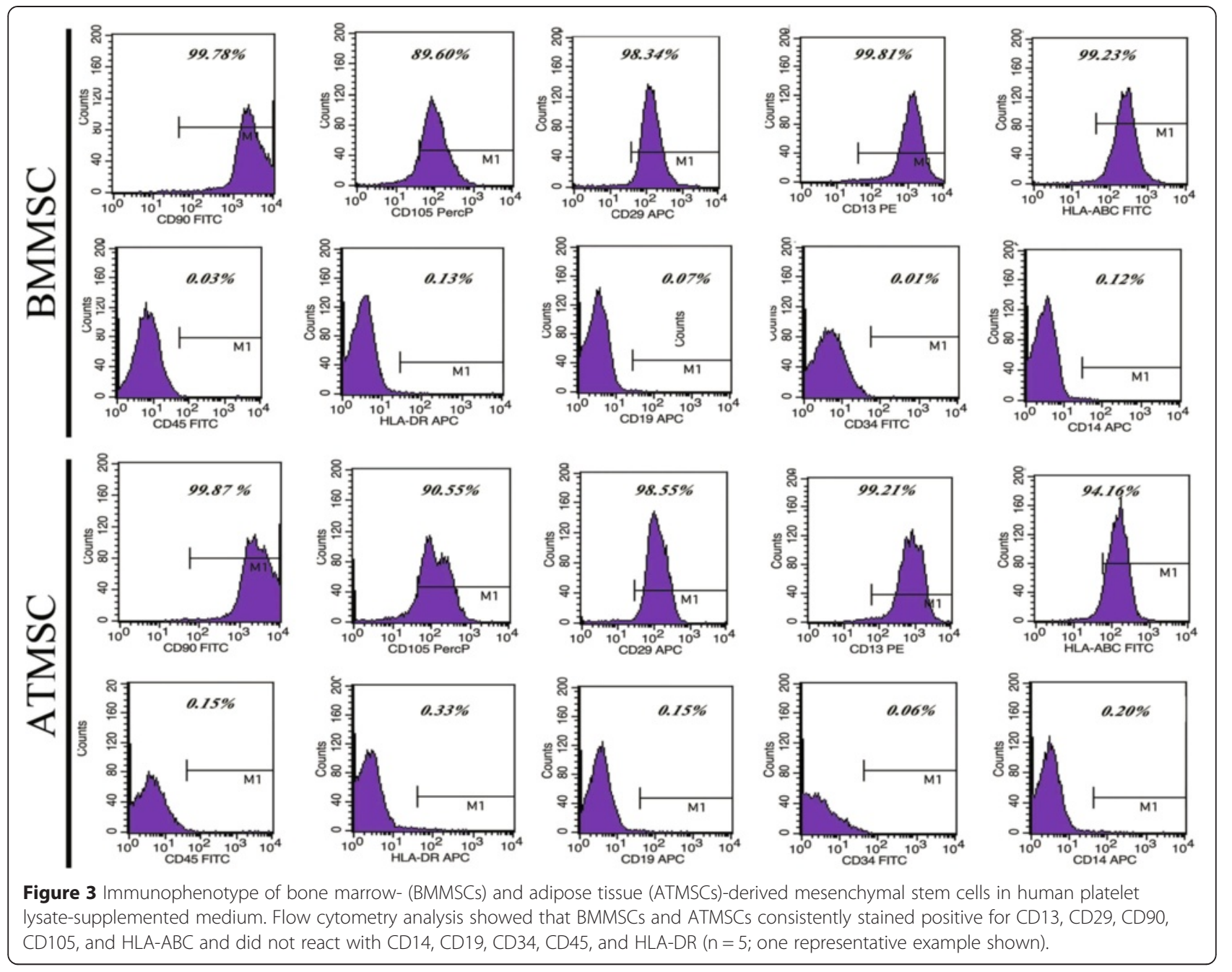

cultured in FBS exhibit different cell morphology, representing heterogeneous populations [39]. In this study, both BMMSCs and ATMSCs exhibit heterogeneous morphology with various shapes at the first hPLsupplemented culture phase, with the morphology becoming gradually homogeneous with successive passages. Both types of cells show a similar fibroblast-like (elongated spindle) morphology in parallel or vortex-like patterns. The possibility of some resting mature cell types within the MSC layer after the first step and the high proliferative rate leads to the culture of successive passages to obtain a large amount of pure MSCs. In addition, a possibility is that MSCs in hPL-supplemented medium are thinner and smaller in morphology and size compared with those in FBS [23]. In the present study, BMMSCs and ATMSCs in hPL-supplemented medium are positive for specific MSC markers (CD13, CD105) and cell adhesion molecules (CD29, CD90) in agreement with earlier reports. Furthermore, MSCs are very low $(<0.5 \%)$ in all hematopoietic cell markers such as CD14, CD19, CD34, and CD45, showing that BMMSCs and
ATMSCs in hPL-supplemented medium have little or no hematopoietic cell contamination. This result is lower than the minimal criteria proposed by the International Society for Cellular Therapy $(<2 \%)$ and that reported in FBS-supplemented medium, further suggesting BMMSCs and ATMSCs in hPL-supplemented medium are nearly homogeneous populations compared with those in FBSsupplemented cultures. Interestingly, both types of cells express HLA-ABC $(>90 \%)$ but not HLA-DR $(<0.5 \%)$, consistent with the result under FBS-supplemented culture in previous reports. Both BMMSCs and ATMSCs reveal very similar expression patterns of surface markers in agreement with the FBS-based comparative phenotypic analysis described earlier [40,41].

Multilineage differentiation potential is the most wellestablished characteristic of MSCs and thus is considered the hallmark of these cells. In the present study, BMMSCs in hPL-supplemented culture exhibit superior capacity for osteogenic and chondrogenic differentiation but a similar capacity for adipogenic differentiation when compared with ATMSCs. According to comparative 
A

BMMSC

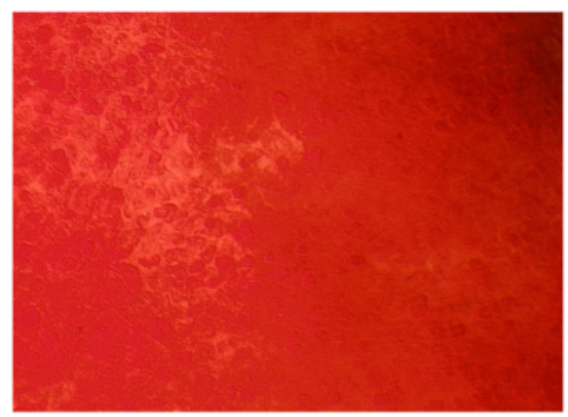

B

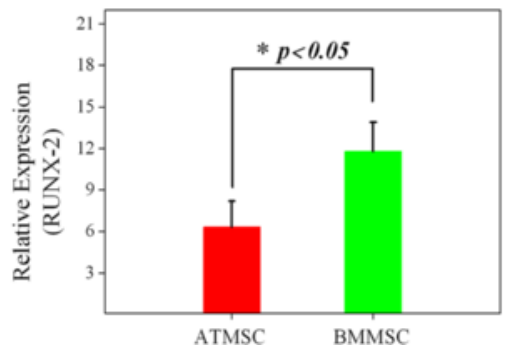

ATMSC
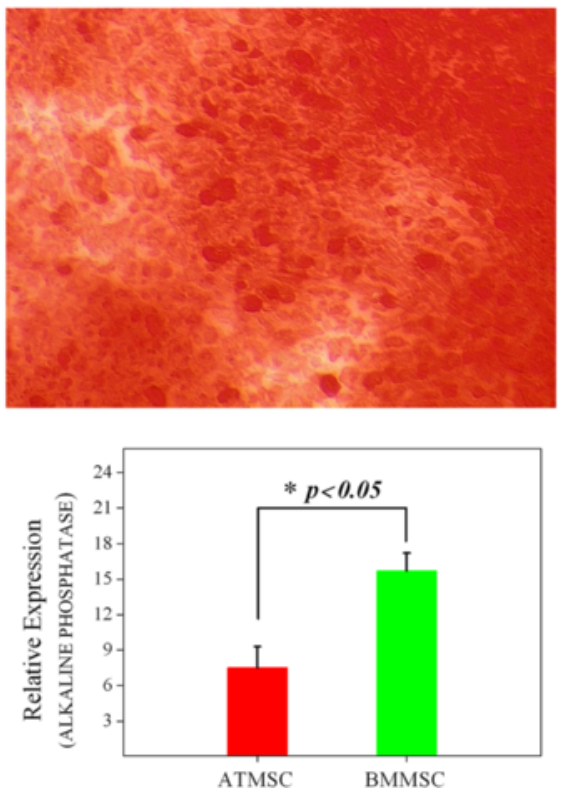

Figure 4 Osteogenic differentiation potential of bone marrow- (BMMSCs) and adipose tissue (ATMSCs)-derived mesenchymal stem cells in human platelet lysate-supplemented medium. (A) Alizarin Red staining of BMMSCs and ATMSCs. Magnification $\times 100$. (B) Quantitative assessment of mRNA expression. Values are shown as mean \pm standard deviation; $\mathrm{n}=5$. ${ }^{*} P<0.05$.

A

BMMSC

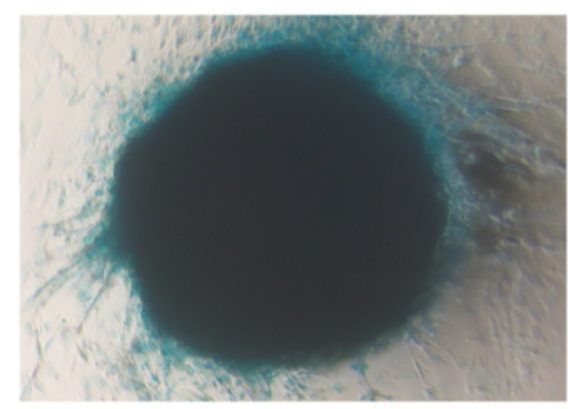

B

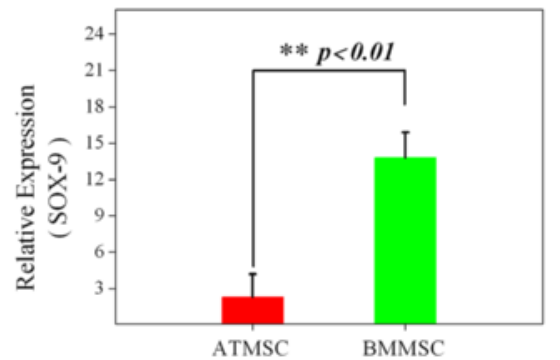

ATMSC
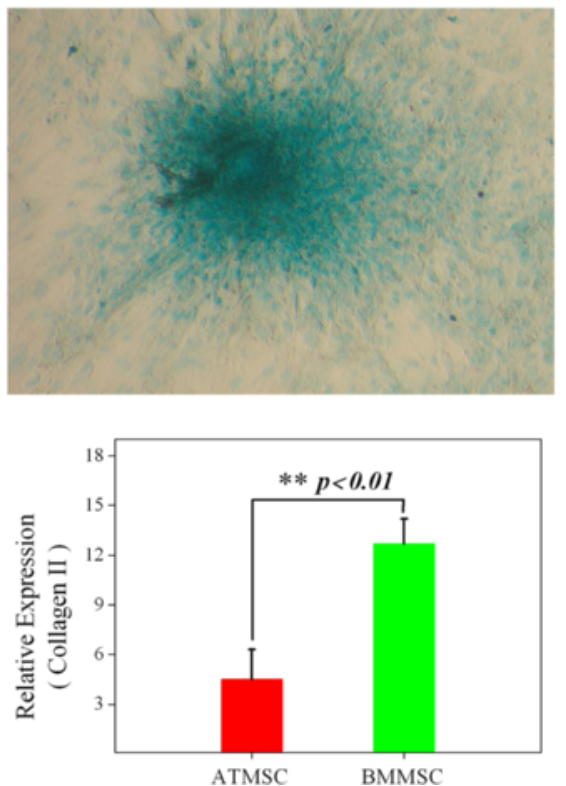

Figure 5 Chondrogenic differentiation potential of bone marrow- (BMMSCs) and adipose tissue (ATMSCs)-derived mesenchymal stem cells in human platelet lysate-supplemented medium. (A) Alcian Blue staining of BMMSCs and ATMSCs. Magnification × 100. (B) Quantitative assessment of mRNA expression. Values are shown as mean \pm standard deviation; $n=5$. ${ }^{*} P<0.01$. 
A

BMMSC

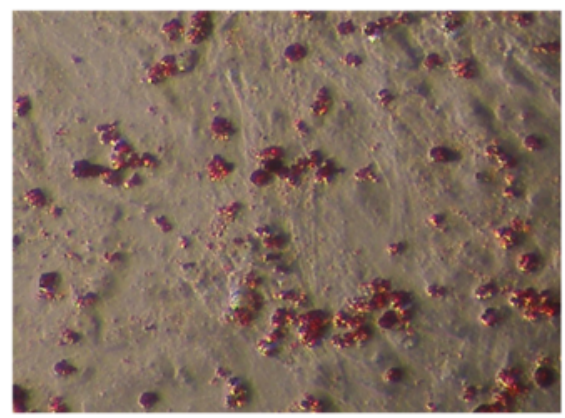

B

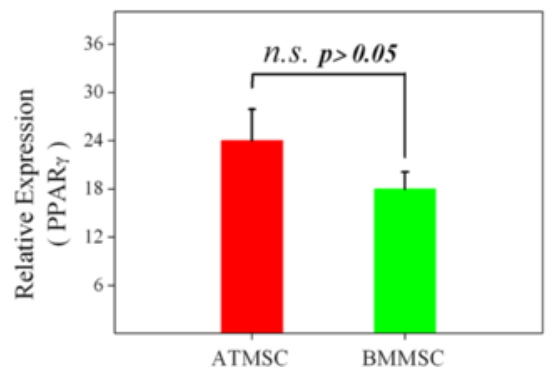

ATMSC
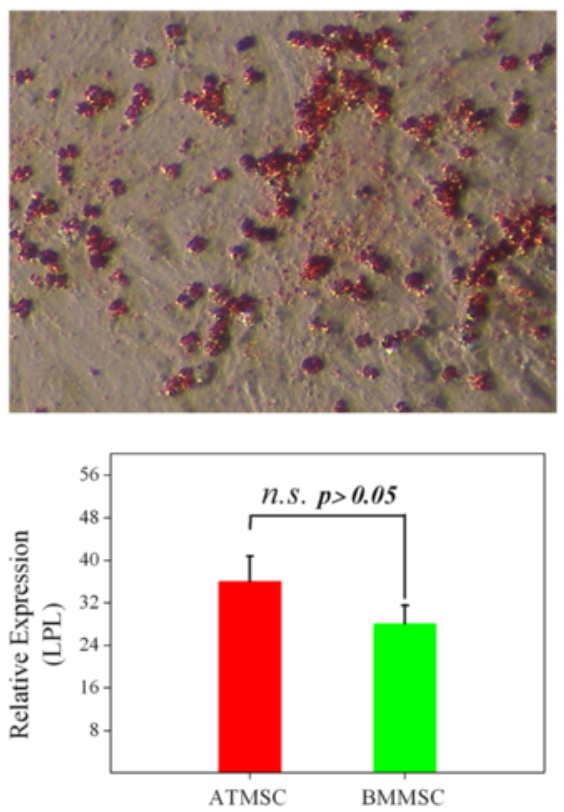

Figure 6 Adipogenic differentiation potential of bone marrow- (BMMSCs) and adipose tissue (ATMSCs)-derived mesenchymal stem cells in human platelet lysate-supplemented medium. (A) Oil Red O staining of BMMSCs and ATMSCs. Magnification $\times 200$. (B) Quantitative assessment of mRNA expression. Values are shown as mean \pm standard deviation; $n=5$. n.s., not significant.
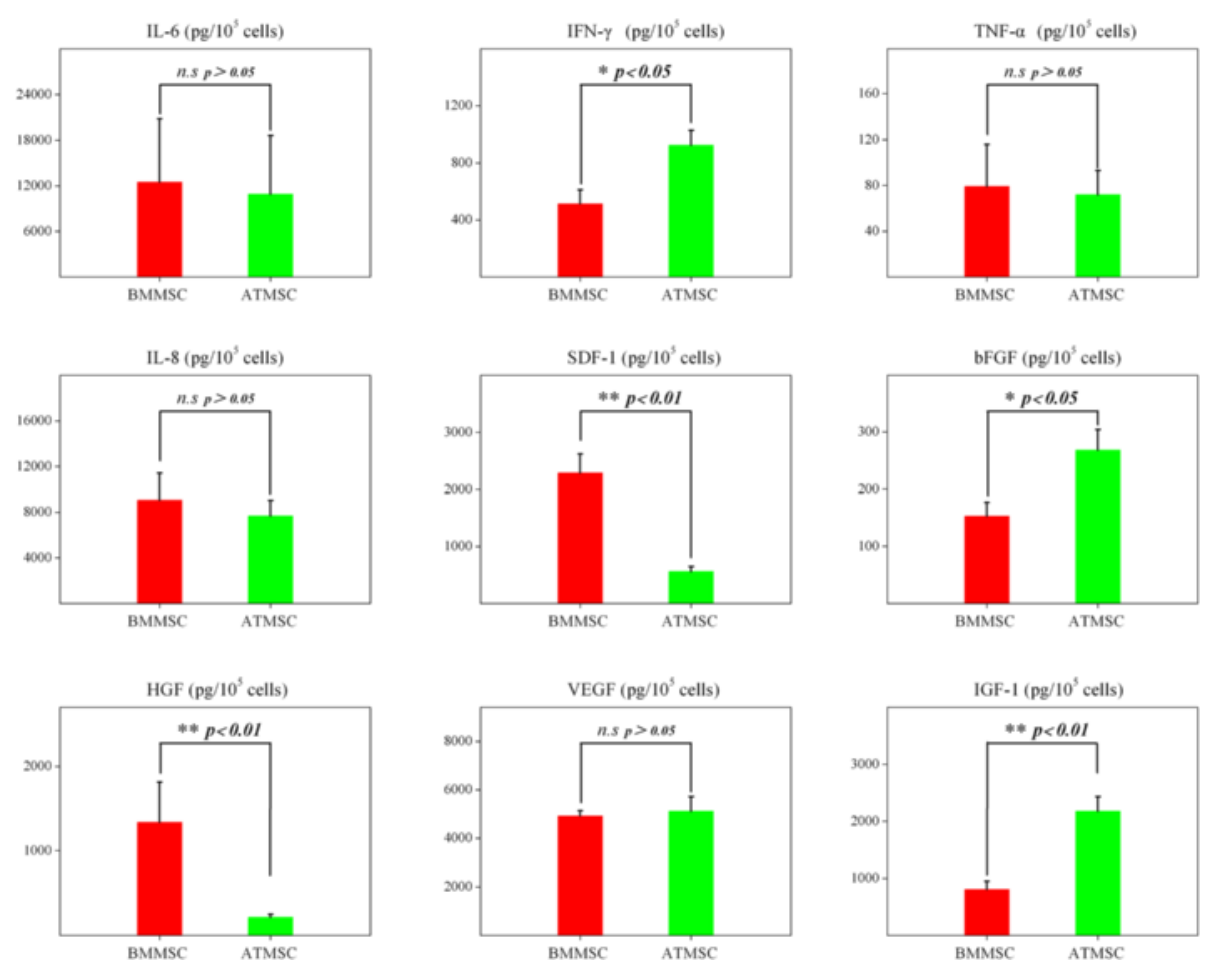

Figure 7 Quantification of cytokines, growth factors, and chemokines (pg/10 5 cells) of bone marrow- (BMMSCs) and adipose tissue (ATMSCs)-derived mesenchymal stem cells. Values are shown as mean \pm standard deviation; $\mathrm{n}=5$. ${ }^{*} P<0.05,{ }^{* *} P<0.01$. bFGF, basic fibroblast growth factor; HGF, hepatocyte growth factor; IFN, interferon; IGF, insulin-like growth factor; IL, interleukin; n.s., not significant; SDF-1, stem cell-derived factor-1; TNF, tumor necrosis factor; VEGF, vascular endothelial growth factor. 

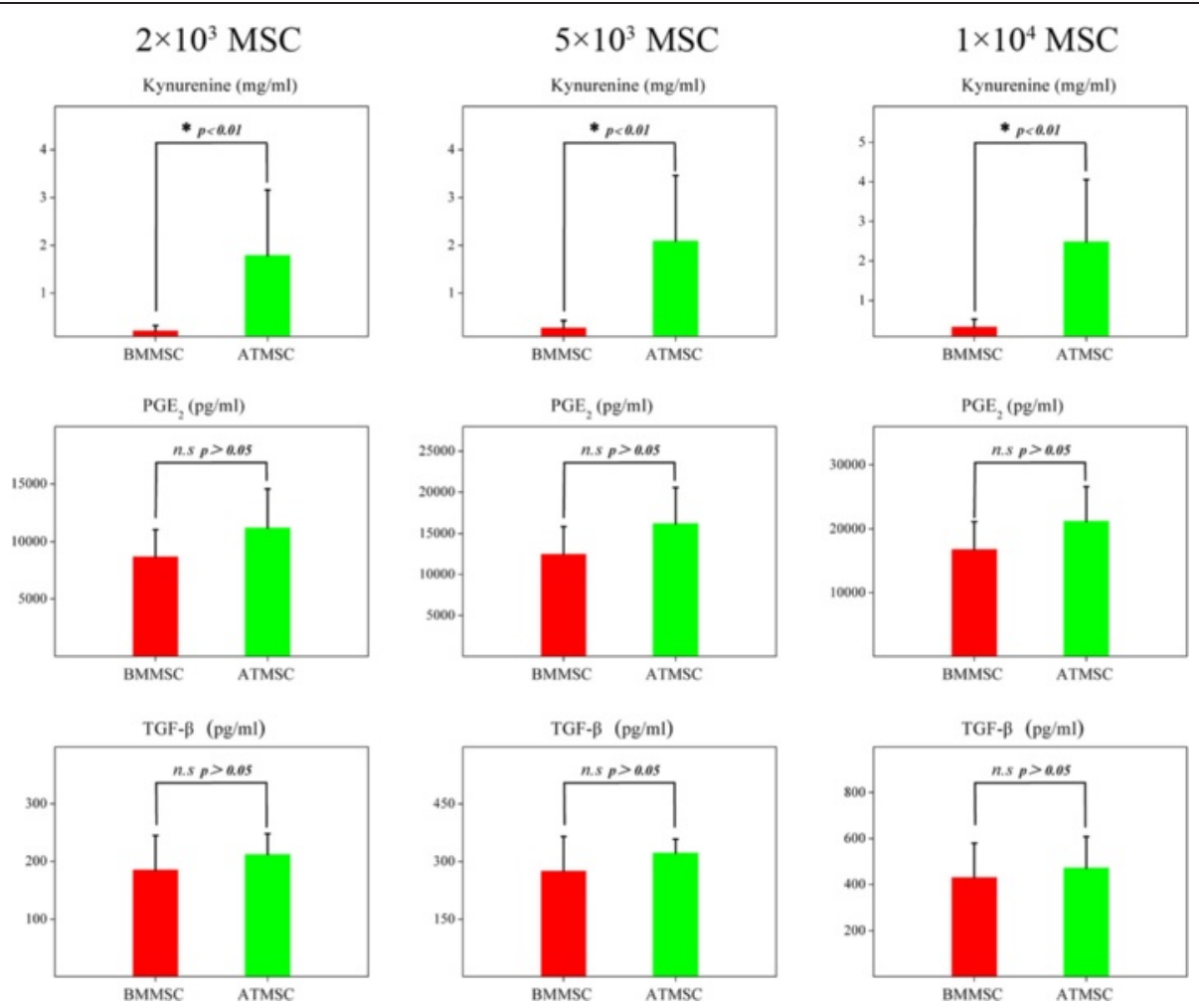

Figure 8 Quantification of immunomodulatory factor ( $\mathrm{pg} / \mathrm{mL}$ ) of bone marrow- (BMMSCs) and adipose tissue (ATMSCs)-derived mesenchymal stem cells. Values are shown as mean \pm standard deviation; $n=5$. ${ }^{*} P<0.01$. MSC, mesenchymal stem cell; n.s., not significant; $P G E_{2}$, prostaglandin $\mathrm{E}_{2} ; \mathrm{TGF}$, transforming growth factor.

analysis of multilineage differentiation of BMMSCs and ATMSCs in FBS-supplemented medium as described earlier, similar patterns of osteogenic and chondrogenic differentiation are demonstrated between the two types of cells in FBS-supplemented medium [42]. On the contrary, ATMSCs have higher adipogenic differentiation potential than BMMSCs [42], but similar adipogenic differentiation capacity between the two types of cells in FBSsupplemented medium is also reported [43]. This may be related to the different differentiation medium and cell passage.

Cell-based therapies need viable and ample numbers of cells for regenerative medicine. In this study, we aim to optimize MSC culture under xeno-free conditions and scale up MSCs in preparation for potential clinical use. Sufficient quantities of MSCs can be scaled up in hPL-supplemented cultures in 5 passages at a seeding density of 2,000 cells $/ \mathrm{cm}^{2}$, considering that a $75-\mathrm{kg}$ patient needs approximately 1 to $5 \times 10^{6}$ MSCs per kilogram body weight for transplantation. Based on a clinical point of view, we therefore suggest that MSCs at passage 5 be used for evaluation of their characteristics. For autologous therapies, the cells should be available soon after injury. In hPL-supplemented cultures, ATMSCs exhibit a significantly greater number of PD than BMMSCs, showing the higher proliferative potential of ATMSCs. Similar patterns were seen in FBS as described previously [43], but a previous study has reported that BMMSCs in FBS show more PD than ATMSCs in passages 2 to 5 [41]. In addition, BMMSCs in the hPL yield similar CFU numbers as ATMSCs. A previous study has reported that the abundance of CFU$\mathrm{F}$ of ATMSCs in FBS is significantly greater than that of BMMSCs [39], but another study shows that BMMSCs form more colonies than ATMSCs in passage 3 [41]. A possible explanation might be that several rich growth factors in hPL can stimulate colonies [24].

It has been suggested that the administration of MSCderived conditioned medium in experimental models of acute organ injury is as effective as the administration of MSCs in some cases $[44,45]$, indicating essential participation of paracrine mechanisms in diminishing pathology. These paracrine factors include different types of cytokines, such as growth factors, inflammatory cytokines and chemoattractants [46]. Increasing evidence supports the notion that the mechanism of functional benefit after MSC implantation is predominantly dependent on paracrine effects [29-31]. We thus compare the expression of growth factors, cytokines and chemokines in BMMSCs and ATMSCs expanded in 
hPL-supplemented conditions, and find a suitable cell source for cell therapy. bFGF, HGF, IGF-1, and VEGF, several well-demonstrated growth factors in cell-based tissue repair, are recently shown to be effective in different models of acute renal, lung, hepatic, myocardial and neural injury [29]. However, their in-depth paracrine mechanisms require further elucidation. Further studies comparing the importance of these four growth factors for the repair of different types of tissues are necessary to determine which growth factor is more effective for specific applications. BMMSCs secrete higher levels of HGF, but lower levels of bFGF and IGF-1, and similar levels of VEGF compared with ATMSCs. The potential for minimally invasive delivery of MSCs by intravenous infusion is enormous for therapeutic applications, and efficient homing of MSCs to the site of injury is critical for inducing tissue repair and regeneration and would also reduce the clinical dose of cells required to achieve a therapeutic effect. Based on the original anatomic locations of BMMSCs and ATMSCs, they could possibly migrate to different sites after systemic delivery and prove to be more effective for specific applications. The homing ability can be attributed to the chemokine expression of MSCs [29]. It has been suggested that SDF-1, a small cytokine belonging to the chemokine family, could augment the mobilization, migration, recruitment, and entrapment of MSCs [29]. Experimental and clinical data have demonstrated that SDF-1 plays an important role in the mobilization and homing of BMMSCs [47]. In this study, the level of SDF-1 is significantly higher in BMMSCs compared with ATMSCs, showing that BMMSCs have stronger migration capacity. This result implies that less BMMSCs are required to achieve a therapeutic effect. A wide range of expression of chemokines and chemokine receptors of MSCs is needed in further research. The data suggest that BMMSCs and ATMSCs need to be explored further for distinct therapeutic roles. Studying the expression levels of growth factors, cytokines and chemokines could facilitate our understanding of their contribution to cell therapy [15]. Clearly, more experiments are required to flesh out the ideas described in this paper.

The immunomodulation effect of MSCs is to a large extent mediated via inflammatory cytokines. Several cytokines have been proposed to play a role in the immunomodulation effect of MSCs, including IFN- $\gamma$, TNF- $\alpha$ and IL-6 [45]. It has been demonstrated that IFN- $\gamma$ is an important cytokine that regulates the immunomodulatory functions of MSCs [48]. Some studies have reported the influence of media composition or cell source on MSC immunomodulation [4,48]. However, few studies to date have examined the effects of cell source based on hPL. Our comparative study shows a stronger expression of IFN- $\gamma$ in ATMSCs, which suggest that ATMSCs may have superior immunomodulatory effects. Functional study demonstrates that ATMSCs exhibit greater IDO activity compared with BMMSCs, demonstrating that ATMSCs may have more potent immunomodulatory effects than BMMSCs, similar to previous results in FBS medium. Other studies have reported that immunomodulatoryrelated cytokines such as $\mathrm{PGE}_{2}$, TGF- $\beta$, and IDO secreted by MSCs, or by immune cells in response to MSCs, play a major role in MSC-mediated immunomodulation [35]. Clinically, the immunomodulatory properties of MSCs can be used to enhance engraftment and to reduce the incidence of the graft-versus-host disease after allogeneic hematopoietic stem cell transplantation. Our data indicates that ATMSCs might be substituted for BMMSCs for treatment of allogeneic conflicts. Further larger and functional studies are needed to confirm the prediction (including other immune-related cytokines and the action on $\mathrm{T}$ cells, natural killer cells, and dendritic cells).

\section{Conclusions}

ATMSCs have biological advantages in proliferative capacity, secreted proteins (bFGF, IFN- $\gamma$, and IGF-1), and immunomodulatory effects, but BMMSCs have advantages in osteogenic and chondrogenic differentiation potential and secreted proteins (SDF-1 and HGF); these biological advantages should be considered systematically when choosing the MSC source for a specific clinical application.

\section{Abbreviations}

AT: adipose tissue; bFGF: basic fibroblast growth factor; BM: bone marrow; CFU-F: colony-forming unit-fibroblast; CPD: cumulative population doubling; DMEM: Dulbecco's modified Eagle's medium; ELISA: enzyme-linked immunosorbent assay; FBS: fetal bovine serum; HGF: hepatocyte growth factor; hPL: human platelet lysate; IDO: indoleamine 2,3-dioxygenase; IFN: interferon; IGF: insulin-like growth factor; IL: interleukin; IMDM: Iscove's modified Dulbecco's medium; MSC: mesenchymal stem cell; PBS: phosphatebuffered saline; PD: population doubling; $\mathrm{PGE}_{2}$ : prostaglandin $\mathrm{E}_{2} ;$ PRP: platelet rich plasma; SDF-1: stem cell-derived factor-1; TGF: transforming growth factor; TNF: tumor necrosis factor; VEGF: vascular endothelial growth factor.

\section{Competing interests}

The authors declare that they have no competing interests.

\section{Authors' contributions}

$X Y W, J B T$ and XXY made contributions to the design of experiments, collection of data, analysis and interpretation of data, and gave final approval of the manuscript. ZJM made contributions to the design of the study, coordination, analysis and interpretation of data, and manuscript revision. JLZ and QFZ made contributions to analysis and interpretation of data, writing and critically revising the manuscript, and gave final approval of the version to be published. GBZ and CYL made contributions to the conception and design, drafting the manuscript, and gave final approval of the version to be published. All authors read and approved the final manuscript.

\section{Acknowledgments}

This work was supported by grants from the National Natural Science Foundation of China (grant no. 30850045).

\section{Author details}

${ }^{1}$ China Military Institute of Chinese Medicine, 302 Military Hospital, Beijing 100039, China. ${ }^{2}$ School of Pharmacy, Chengdu University of Traditional 
Chinese Medicine, Chengdu 610000, China. ${ }^{3}$ Beijing Institute of Life Science Translational Medicine Research Center, Beijing 100085, China. ${ }^{4}$ Shandong Medicinal Biotechnology Centre, Shandong Academy of Medical Sciences, Jinan 250000, China. ${ }^{5}$ School of Pharmacy, Changchun University of Traditional Chinese Medicine, Changsha 410208, China. ${ }^{6}$ Jilin Vocational College of Industry and Technology, Jilin 132013, China. ${ }^{7}$ The First Affiliated Hospital, Hebei North University, Zhangjiakou 075000, China. ${ }^{8}$ Department of Pharmacy, Beijing Friendship Hospital, Capital Medical University, Beijing 100050, China

Received: 12 July 2014 Revised: 24 November 2014 Accepted: 25 March 2015 Published online: 13 April 2015

\section{References}

1. Zou JP, Huang S, Peng Y, Liu HW, Cheng B, Fu XB, et al. Mesenchymal stem cells/multipotent mesenchymal stromal cells (MSCs): potential role in healing cutaneous chronic wounds. Int J Low Extrem Wounds. 2012;11:244-53.

2. da Silva ML, Chagastelles PC, Nardi NB. Mesenchymal stem cells reside in virtually all post-natal organs and tissues. J Cell Sci. 2006;119:2204-13.

3. Hoogduijn MJ, Dor FJ. Mesenchymal stem cells: are we ready for clinical application in transplantation and tissue regeneration? Front Immunol. 2013:4:144.

4. Puissant B, Barreau C, Bourin P, Clavel C, Corre J, Bousquet C, et al. Immunomodulatory effect of human adipose tissue-derived adult stem cells: comparison with bone marrow mesenchymal stem cells. Br J Haematol. 2005:129:118-29.

5. Chung CS, Fujita N, Kawahara N, Yui S, Nam E, Nishimura R. A comparison of neurosphere differentiation potential of canine bone marrow-derived mesenchymal stem cells and adipose-derived mesenchymal stem cells. J Vet Med Sci. 2013;75:879-86.

6. Cooper GM, Durham EL, Cray Jr JJ, Bykowski MR, DeCesare GE, Smalley MA, et al. Direct comparison of progenitor cells derived from adipose, muscle, and bone marrow from wild-type or craniosynostotic rabbits. Plast Reconstr Surg. 2011;127:88-97.

7. Danisovic L, Varga I, Polak S, Ulicna M, Hlavackova L, Bohmer D, et al. Comparison of in vitro chondrogenic potential of human mesenchymal stem cells derived from bone marrow and adipose tissue. Gen Physiol Biophys. 2009;28:56-62.

8. De Ugarte DA, Morizono K, Elbarbary A, Alfonso Z, Zuk PA, Zhu M, et al. Comparison of multi-lineage cells from human adipose tissue and bone marrow. Cells Tissues Organs. 2003;174:101-9.

9. Vishnubalaji R, Al-Nbaheen M, Kadalmani B, Aldahmash A, Ramesh T. Comparative investigation of the differentiation capability of bone-marrowand adipose-derived mesenchymal stem cells by qualitative and quantitative analysis. Cell Tissue Res. 2012:347:419-27.

10. Elman JS, Li M, Wang F, Gimble JM, Parekkadan B. A comparison of adipose and bone marrow-derived mesenchymal stromal cell secreted factors in the treatment of systemic inflammation. J Inflamm. 2014;11:1.

11. Ertas G, Ural E, Ural D, Aksoy A, Kozdag G, Gacar G, et al. Comparative analysis of apoptotic resistance of mesenchymal stem cells isolated from human bone marrow and adipose tissue. ScientificWorldJournal. 2012:2012:105698.

12. Rasmussen JG, Frobert O, Holst-Hansen C, Kastrup J, Baandrup U, Zachar V, et al. Comparison of human adipose-derived stem cells and bone marrowderived stem cells in a myocardial infarction model. Cell Transplant. 2014;23:195-206

13. Huang Jl, Kazmi N, Durbhakula MM, Hering TM, Yoo JU, Johnstone B. Chondrogenic potential of progenitor cells derived from human bone marrow and adipose tissue: a patient-matched comparison. J Orthop Res. 2005;23:1383-9.

14. Hsiao ST, Asgari A, Lokmic Z, Sinclair R, Dusting GJ, Lim SY, et al. Comparative analysis of paracrine factor expression in human adult mesenchymal stem cells derived from bone marrow, adipose, and dermal tissue. Stem Cells Dev. 2012;21:2189-203.

15. Ahmadian Kia N, Bahrami AR, Ebrahimi M, Matin MM, Neshati Z Almohaddesin MR, et al. Comparative analysis of chemokine receptor's expression in mesenchymal stem cells derived from human bone marrow and adipose tissue. J Mol Neurosci. 2011;44:178-85.

16. Muller I, Kordowich S, Holzwarth C, Spano C, Isensee G, Staiber A, et al. Animal serum-free culture conditions for isolation and expansion of multipotent mesenchymal stromal cells from human BM. Cytotherapy. 2006:8:437-44.

17. van der Valk J, Brunner D, De Smet K, Fex Svenningsen A, Honegger P, Knudsen LE, et al. Optimization of chemically defined cell culture mediareplacing fetal bovine serum in mammalian in vitro methods. Toxicol In Vitro. 2010;24:1053-63.

18. Spees JL, Gregory CA, Singh H, Tucker HA, Peister A, Lynch PJ, et al. Internalized antigens must be removed to prepare hypoimmunogenic mesenchymal stem cells for cell and gene therapy. Mol Ther. 2004;9:747-56.

19. Lange C, Cakiroglu F, Spiess AN, Cappallo-Obermann H, Dierlamm J, Zander AR. Accelerated and safe expansion of human mesenchymal stromal cells in animal serum-free medium for transplantation and regenerative medicine. J Cell Physiol. 2007;213:18-26.

20. Capelli C, Domenghini M, Borleri G, Bellavita P, Poma R, Carobbio A, et al. Human platelet lysate allows expansion and clinical grade production of mesenchymal stromal cells from small samples of bone marrow aspirates or marrow filter washouts. Bone Marrow Transplant. 2007:40:785-91.

21. Centeno CJ, Schultz JR, Cheever M, Freeman M, Faulkner S, Robinson B, et al. Safety and complications reporting update on the re-implantation of culture-expanded mesenchymal stem cells using autologous platelet lysate technique. Curr Stem Cell Res Ther. 2011;6:368-78.

22. Naaijkens BA, Niessen HW, Prins HJ, Krijnen PA, Kokhuis TJ, de Jong N, et al. Human platelet lysate as a fetal bovine serum substitute improves human adipose-derived stromal cell culture for future cardiac repair applications. Cell Tissue Res. 2012;348:119-30.

23. Schallmoser K, Bartmann C, Rohde E, Reinisch A, Kashofer K, Stadelmeyer E, et al. Human platelet lysate can replace fetal bovine serum for clinical-scale expansion of functional mesenchymal stromal cells. Transfusion. 2007:47:1436-46.

24. Walenda G, Hemeda H, Schneider RK, Merkel R, Hoffmann B, Wagner W. Human platelet lysate gel provides a novel three dimensional-matrix for enhanced culture expansion of mesenchymal stromal cells. Tissue Eng Part C Methods. 2012;18:924-34

25. Gottipamula S, Sharma A, Krishnamurthy S, Majumdar AS, Seetharam RN. Human platelet lysate is an alternative to fetal bovine serum for large-scale expansion of bone marrow-derived mesenchymal stromal cells. Biotechnol Lett. 2012;34:1367-74.

26. Xia W, Li H, Wang Z, Xu R, Fu Y, Zhang X, et al. Human platelet lysate supports ex vivo expansion and enhances osteogenic differentiation of human bone marrow-derived mesenchymal stem cells. Cell Biol Int. 2011:35:639-43.

27. Abdelrazik H, Spaggiari GM, Chiossone L, Moretta L. Mesenchymal stem cells expanded in human platelet lysate display a decreased inhibitory capacity on T- and NK-cell proliferation and function. Eur J Immunol. 2011;41:3281-90

28. Sensebe L, Bourin P, Tarte K. Good manufacturing practices production of mesenchymal stem/stromal cells. Hum Gene Ther. 2011;22:19-26.

29. Meirelles Lda S, Fontes AM, Covas DT, Caplan Al. Mechanisms involved in the therapeutic properties of mesenchymal stem cells. Cytokine Growth Factor Rev. 2009:20:419-27.

30. Mok PL, Leong CF, Cheong SK. Cellular mechanisms of emerging applications of mesenchymal stem cells. Malays J Pathol. 2013;35:17-32.

31. Ozaki K, Sato K, Oh I, Meguro A, Tatara R, Muroi K, et al. Mechanisms of immunomodulation by mesenchymal stem cells. Int J Hematol. 2007;86:5-7.

32. Schallmoser K, Rohde E, Reinisch A, Bartmann C, Thaler D, Drexler C, et al. Rapid large-scale expansion of functional mesenchymal stem cells from unmanipulated bone marrow without animal serum. Tissue Eng Part C Methods. 2008;14:185-96.

33. Parker AM, Shang $H$, Khurgel M, Katz AJ. Low serum and serum-free culture of multipotential human adipose stem cells. Cytotherapy. 2007;9:637-46.

34. Yoshimura H, Muneta T, Nimura A, Yokoyama A, Koga H, Sekiya I. Comparison of rat mesenchymal stem cells derived from bone marrow, synovium, periosteum, adipose tissue, and muscle. Cell Tissue Res. 2007;327:449-62.

35. Zimmermann JA, McDevitt TC. Pre-conditioning mesenchymal stromal cell spheroids for immunomodulatory paracrine factor secretion. Cytotherapy. 2014; 16:331-45.

36. Abdelkhalek NK, Komiya A, Kato-Unoki Y, Somamoto T, Nakao M. Molecular evidence for the existence of two distinct IL-8 lineages of teleost CXCchemokines. Fish Shellfish Immunol. 2009;27:763-7.

37. Zhou Y, Guan X, Yu M, Wang X, Zhu W, Wang C, et al. Angiogenic/ osteogenic response of BMMSCs on bone-derived scaffold: effect of hypoxia and role of PI3K Akt-mediated VEGF-VEGFR pathway. Biotechnol J. 2014. 
38. Dominici M, Le Blanc K, Mueller I, Slaper-Cortenbach I, Marini F, Krause D, et al. Minimal criteria for defining multipotent mesenchymal stromal cells. The International Society for Cellular Therapy position statement. Cytotherapy. 2006:8:315-7.

39. Mosna F, Sensebe L, Krampera M. Human bone marrow and adipose tissue mesenchymal stem cells: a user's guide. Stem Cells Dev. 2010;19:1449-70.

40. Secunda R, Vennila R, Mohanashankar AM, Rajasundari M, Jeswanth S, Surendran R. Isolation, expansion and characterisation of mesenchymal stem cells from human bone marrow, adipose tissue, umbilical cord blood and matrix: a comparative study. Cytotechnology. 2014. [Epub ahead of print]

41. Jin HJ, Bae YK, Kim M, Kwon SJ, Jeon HB, Choi SJ, et al. Comparative analysis of human mesenchymal stem cells from bone marrow, adipose tissue, and umbilical cord blood as sources of cell therapy. Int J Mol Sci. 2013;14:17986-8001

42. Peng $L$, Jia Z, Yin X, Zhang X, Liu Y, Chen $P$, et al. Comparative analysis of mesenchymal stem cells from bone marrow, cartilage, and adipose tissue. Stem Cells Dev. 2008;17:761-73.

43. Nakanishi C, Nagaya N, Ohnishi S, Yamahara K, Takabatake S, Konno T, et al. Gene and protein expression analysis of mesenchymal stem cells derived from rat adipose tissue and bone marrow. Circ J. 2011;75:2260-8.

44. Khubutiya MS, Vagabov AV, Temnov AA, Sklifas AN. Paracrine mechanisms of proliferative, anti-apoptotic and anti-inflammatory effects of mesenchymal stromal cells in models of acute organ injury. Cytotherapy. 2014;16:579-85.

45. Xagorari A, Siotou E, Yiangou M, Tsolaki E, Bougiouklis D, Sakkas L, et al. Protective effect of mesenchymal stem cell-conditioned medium on hepatic cell apoptosis after acute liver injury. Int J Clin Exp Pathol. 2013;6:831-40.

46. Liang X, Ding Y, Zhang Y, Tse HF, Lian Q. Paracrine mechanisms of mesenchymal stem cell-based therapy: current status and perspectives. Cell Transplant. 2014;23:1045-59.

47. Elmadbouh I, Haider H, Jiang S, Idris NM, Lu G, Ashraf M. Ex vivo delivered stromal cell-derived factor-1alpha promotes stem cell homing and induces angiomyogenesis in the infarcted myocardium. J Mol Cell Cardiol. 2007:42:792-803

48. Lee JM, Jung J, Lee HJ, Jeong SJ, Cho KJ, Hwang SG, et al. Comparison of immunomodulatory effects of placenta mesenchymal stem cells with bone marrow and adipose mesenchymal stem cells. Int Immunopharmacol. 2012;13:219-24.

\section{Submit your next manuscript to BioMed Central and take full advantage of:}

- Convenient online submission

- Thorough peer review

- No space constraints or color figure charges

- Immediate publication on acceptance

- Inclusion in PubMed, CAS, Scopus and Google Scholar

- Research which is freely available for redistribution 